\title{
RESEARCH
}

Open Access

\section{Transplantation of human endometrial perivascular cells with elevated CYR61 expression induces angiogenesis and promotes repair of a full-thickness uterine injury in rat}

\author{
Zhongxun $\mathrm{Li}^{1,2 \dagger}$, Guijun $\mathrm{Yan}^{2 \dagger}$, Qiang Diao ${ }^{3 \dagger}$, Fei Yu ${ }^{4}$, Xin'an $\mathrm{Li}^{5}$, Xiaoqiang Sheng ${ }^{2}$, Yong Liu ${ }^{6}$, Yimin Dai ${ }^{5}$,
} Huaijun Zhou ${ }^{5}$, Xin Zhen ${ }^{2}$, Yali Hu², Bruno Péault ${ }^{7}$, Lijun Ding ${ }^{2,7,8^{*}}$, Haixiang Sun ${ }^{2,9^{*}}$ and Hairong $\mathrm{Li}^{*{ }^{*}}$

\begin{abstract}
Background: Disruptions of angiogenesis can have a significant effect on the healing of uterine scars. Human endometrial perivascular cells (CD146+PDGFR $\beta+$ ) function as stem cells in the endometrium. Cysteine-rich angiogenic inducer 61 (CYR61) plays an important role in vascular development. The purpose of this study was to observe the effects of the transplantation of human endometrial perivascular cells (En-PSCS) overexpressing CYR61 on structural and functional regeneration in rat models of partial full-thickness uterine excision.

Methods: We first sorted human En-PSCs from endometrial single-cell suspensions by flow cytometry. Human En-PSCs expressing low or high levels of CYR61 were then generated via transfection with a CYR61-specific small interfering ribonucleic acid (si-CYR61) construct or overexpression plasmid. To establish a rat model of uterine injury, a subset of uterine wall was then resected from each uterine horn in experimental animals. Female rats were randomly assigned to five groups, including a sham-operated group and four repair groups that received either PBS loaded on a collagen scaffold (collagen/PBS), En-PSCs loaded on a collagen scaffold (collagen/En-PSCs), En-PSCs with low CYR61 expression loaded on a collagen scaffold (collagen/si-CYR61 En-PSCs), and En-PSCs overexpressing CYR61 loaded on a collagen scaffold (collagen/ov-CYR61 En-PSCs). These indicated constructs were sutured in the injured uterine area to replace the excised segment. On days 30 and 90 after transplantation, a subset of rats in each group was sacrificed, and uterine tissue was recovered and serially sectioned. Hematoxylin and eosin staining and immunohistochemical staining were then performed. Finally, the remaining rats of each group were mated with fertile male rats on day 90 for a 2-week period.

\footnotetext{
*Correspondence: xmljding@163.com; stevensunz@163.com; lihairong20030829@163.com

'Zhongxun Li, Guijun Yan and Qiang Diao contributed equally to this work.

${ }^{2}$ Center for Reproductive Medicine, Department of Obstetrics and

Gynecology, the Affiliated Drum Tower Hospital of Nanjing University

Medical School, Nanjing 210008, China

'Department of Histology and Embryology of Shanxi Medical University,

Taiyuan 030001, China

Full list of author information is available at the end of the article
}

(c) The Author(s). 2019 Open Access This article is distributed under the terms of the Creative Commons Attribution 4.0 International License (http://creativecommons.org/licenses/by/4.0/), which permits unrestricted use, distribution, and reproduction in any medium, provided you give appropriate credit to the original author(s) and the source, provide a link to the Creative Commons license, and indicate if changes were made. The Creative Commons Public Domain Dedication waiver (http://creativecommons.org/publicdomain/zero/1.0/) applies to the data made available in this article, unless otherwise stated. 
(Continued from previous page)

Results: Sorted En-PSCs expressed all recognized markers of mesenchymal stem cells (MSCs), including CD10, CD13, CD44, CD73, CD90, and CD105, and exhibited differentiation potential toward adipocytes, osteoblasts, and neuron-like cells. Compared with En-PSCs and En-PSCs with low CYR61 expression, En-PSCs with elevated CYR61 expression enhanced angiogenesis by in vitro co-culture assays. At day 90 after transplantation, blood vessel density in the collagen/ov-CYR61 En-PSCs group (11.667 \pm 1.287$)$ was greater than that in the collagen/En-PSCs group (7.167 \pm 0.672$)$ $(P<0.05)$ and the collagen/si-CYR61 En-PSCs group (3.750 \pm 0.906$)(P<0.0001)$. Pregnancy rates differed among groups, from 40\% in the collagen/PBS group to 80\% in the collagen/En-PSCs group, 12.5\% in the collagen/si-CYR61 En-PSCs group, and 80\% in the collagen/ov-CYR61 En-PSCs group. In addition, four embryos were evident in the injured uterine horns of the collagen/ov-CYR61 En-PSCs group, while no embryos were identified in the injured uterine horns of the collagen/PBS group.

Conclusions: The results showed that CYR61 plays an important role in angiogenesis. Collagen/ov-CYR61 En-PSCs promoted endometrial and myometrial regeneration and induced neovascular regeneration in injured rat uteri. The pregnancy rate of rats treated with transplantation of collagen/En-PSCs or collagen/ov-CYR61 En-PSCs was improved. Moreover, the number of embryos implantation on the injured area in uterus was increased after transplantation of collagen/ov-CYR61 En-PSCs.

Keywords: Endometrial perivascular cells, CYR61, Uterine injury, Neovascularization, Fertility

\section{Background}

Asherman syndrome can occur following uterine curettage, instrumentation, or infections in the pregnant or recently pregnant uterine cavity. It is often accompanied by scarring of the endometrium, hypomenorrhea, and abortion [1]. A previous study revealed that among women whose implantation sites were close to or crossing a scarred region, $55 \%$ or $88 \%$, respectively suffered a spontaneous abortion, as compared with just $22 \%$ of women with implantation sites away from the scarred region. Indeed, the presence of such scarring reduces the likelihood of successful embryo implantation when the implantation site is close to the scar [2]. In a 10-year study including 638 women with Asherman syndrome, the chance of spontaneous recurrence of adhesion was $20.8 \%$ even when the initial grade of adhesions was grade 1 [3]. Surgical management via hysteroscopic lysis of adhesions is major and an effective treatment for uterine scars, but there are currently no effective means for preventing recurrence [4]. The microvascular density in patients with Asherman syndrome who respond to surgery is significantly increased as compared with that in patients who do not respond to surgery, suggesting that angiogenesis in the scar regions may affect endometrial repair [5]. Previous study using mesenchymal stem cells (MSCs) to repair the fullthickness injury in rat uterus has suggested that angiogenesis can be enhanced at a certain extent [6].

The human endometrium has a remarkable regenerative capacity and can grow 4-6 mm within 5-6 days after onset of menstruation [7]. In 2004, the clonogenicity of human endometrial epithelial and stromal cells was first identified [8]. In 2007, functional evidence for the existence of human and mouse endometrial stem cells was further discussed [9]. Subsequently, the markers CD146 and PDGFR $\beta$ were used to identify the endometrial stem cells. While these markers identify a perivascular region in both the functionalis and basalis of the human endometrium $[10,11]$, they are also expressed by perivascular cells, indicating that perivascular cells are closely related to endometrial mesenchymal stem cells (eMSCs) [10, 12, 13].

Perivascular cells are present at intervals along the walls of capillaries [14], have myogenic potential, exhibit migratory ability, and give rise to MSCs [12]. Perivascular cells are multipotent and can differentiate into chondrocytes, adipocytes, phagocytes, osteoblasts, and granulocytes. They express MSCs markers such as CD105, CD73, CD90, and CD44 [15]. Given their key properties, it is thus possible that endometrial perivascular cells (En-PSCs) may have a superior ability to regenerate scarred uterine tissue [16-19].

Cysteine-rich angiogenic inducer 61 (CYR61), also known as $\mathrm{CCN}$ family member 1 (CCN1), encoded by the CYR61 gene, is a matricellular protein [20] that is highly expressed in endothelial cells and in smooth muscle cells throughout development and is essential for vascular integrity [21]. CYR61 is essential for cardiovascular development during embryogenesis [22]. In vitro, CYR61 promotes the migration of endothelial cells and stimulates the release of angiogenic factors from the extracellular matrix (ECM), which may contribute to the overall process of neovascularization in vivo [23]. CYR61 is also involved in angiogenesis and tissue repair [22, 24], and perivascular cells-specific loss of CYR61 reduces angiogenic signals in the mouse model of oxygeninduced retinopathy [25]. 
In this context, the aim of this study was to construct En-PSCs expressing different levels of CYR61 and to observe their effects on healing and related outcomes in a rat model of full-thickness uterine injury. In this study, En-PSCs with elevated CYR61 expression loaded on a collagen scaffold induced increased angiogenesis and promote functional regeneration of injured rat uteri. Our findings indicated that En-PSCs with elevated CYR61 expression loaded on a collagen scaffold may support uterine tissue regeneration.

\section{Methods}

\section{Isolation and culture of En-PSCs}

Endometrial tissue samples were obtained from women attending the Center for Reproductive Medicine of Nanjing Drum Tower Hospital from June 2017 to June 2018. All samples were collected with the informed consent of the patients, and approval from the ethics committee was obtained for this study. The tissue was washed twice with sterile D-Hanks solution, the muscle layer was stripped away, and the tissue was then cut up and digested in a mixture of $1 \mathrm{mg} / \mathrm{mL}$ collagenase I, II, and IV and $40 \mu \mathrm{g} / \mathrm{mL}$ deoxyribonuclease. After digestion and centrifugation, red blood cells were lysed for $5 \mathrm{~min}$ and then the cells were resuspended in D-hanks solution at $10^{6} / \mathrm{mL}$. Next, $10 \mu \mathrm{L}$ of anti-CD45-APC-Cy7 (1:100; BD Biosciences, San Jose, CA, USA), anti-CD144-PerCPCy5.5 (1:100; BD Biosciences), anti-CD56-PE-Cy7 (1:100; BD Biosciences), anti-CD34-PE (1:100; BD Biosciences), and anti-CD146-FITC (1:100; BD Biosciences) was added to the cell suspensions at $4{ }^{\circ} \mathrm{C}$ for $15 \mathrm{~min}$ in the dark. Cells were then incubated for 15 min with DAPI (BD Biosciences) for dead cell exclusion. At the same time, the isotype control and blank control were set. Following this incubation, cells were washed twice with Dhanks solution and resuspended at a final volume of $500 \mu \mathrm{L}$ before flow cytometry. En-PSCs, which were identified as CD146+CD34-CD45-CD56-CD144 cells [12], were sorted from these single-cell suspensions and then cultured in DMEM-F12 (Gibco, Grand Island, NY, USA) media supplemented with $10 \%$ fetal bovine serum (FBS; Gibco) and $10 \mathrm{ng} / \mathrm{ml}$ basic fibroblast growth factor (bFGF; Gibco).

\section{Immunofluorescence analysis}

Expression of CD146, CD31, PDGFR $\beta$, and $\alpha$-smooth muscle actin $(\alpha$-SMA) were detected in the endometrium by immunofluorescence staining. Frozen sections of fresh endometrium were fixed in $4 \%$ paraformaldehyde and stained with primary antibodies such as antiCD146 antibody (ab75769, Abcam, Cambridge, MA, USA), anti-CD31 antibody (ab187377, Abcam), antiPDGFR $\beta$ antibody (ab139406, Abcam), and anti- $\alpha$-SMA antibody (M0851, Dako, Glostrup, Denmark) at $4{ }^{\circ} \mathrm{C}$ overnight. Secondary Alexa Fluor 594-conjugated donkey anti-rabbit IgG (1: 1000, Invitrogen, Grand Island, NY, USA), Alexa Fluor 488-conjugated donkey antimouse IgG (1: 1000, Invitrogen), Alexa Fluor 488conjugated donkey anti-rabbit IgG (1: 1000, Invitrogen), or Alexa Fluor 594-conjugated donkey anti-mouse IgG (1: 1000, Invitrogen) were used to stain the tissue. The nuclei were then stained with DAPI (Sigma, St. Louis, MO, USA).

En-PSCs were fixed in $4 \%$ paraformaldehyde and stained with primary antibodies such as anti-PDGFR $\beta$ antibody (ab139406, Abcam), anti-NG2 antibody (ab83178, Abcam), and anti- $\alpha$-SMA antibody (ab5694, Abcam) at $4{ }^{\circ} \mathrm{C}$ overnight. Secondary Alexa Fluor 488conjugated goat anti-rabbit IgG (1: 1000, Invitrogen) or Alexa Fluor 594-conjugated goat anti-rabbit IgG (1: 1000, Invitrogen) were used to stain cells. The nuclei were then stained with DAPI (Sigma), and cells were imaged using a fluorescence confocal microscope (Leica, Wetzlar, Germany).

\section{Flow cytometric analysis}

Cell surface antigens of En-PSCs (passage 6) were analyzed by flow cytometer (BD Biosciences). Single-cell suspensions were harvested in $0.2 \% \mathrm{FBS} / \mathrm{PBS}$. The cells were then incubated for $30 \mathrm{~min}$ with $\mathrm{PE}$-conjugated anti-rat CD34 (BD Pharmingen, San Diego, CA, USA), CD144 (BD Pharmingen), CD56 (BD Pharmingen), CD105 (BD Pharmingen), CD13 (BD Pharmingen), HLA-DR (BD Pharmingen), FITC-conjugated anti-rat CD146 (BD Pharmingen), CD73 (BD Pharmingen), CD90 (BD Pharmingen), CD44 (BD Pharmingen), and CD45 (BD Pharmingen) at $4{ }^{\circ} \mathrm{C}$ for $30 \mathrm{~min}$. The cells were then analyzed via flow cytometer (Becton Dickinson, USA).

\section{Differentiation of En-PSCs}

En-PSCs (passage 6) were assessed for their multipotency using adipogenic, osteogenic, and neural-like differentiation assays. The cells were seeded at a density of $2 \times 10^{4} / \mathrm{cm}^{2}$ in 24 -well plates. Growth media was replaced with the appropriate differentiation medium when cells reached 90\% confluency. Adipogenic and osteogenic induction media (Gibco) were used for differentiation. After 30 days, cells were stained with oil red $\mathrm{O}$ (Sigma) or alizarin red S (Gibco) to identify lipid droplets or calcium deposition, respectively. For neural-like differentiation, pre-induction media containing $10^{-7}$ $\mathrm{mol} / \mathrm{L}$ all-trans-retinoic acid (ATRA; Sigma) and $10 \mathrm{ng} /$ $\mathrm{ml}$ bFGF was added to cells for $24 \mathrm{~h}$ followed by the addition of modified neuronal medium for $6 \mathrm{~h}$. Neurallike differentiation was detected via immunofluorescent staining for neurofilament medium polypeptide (NF-M; 1:100, sc-16143, Santa Cruz Biotechnology, Santa Cruz, 
CA, USA) and neuron-specific enolase (NSE; 1:100, sc292097, Santa Cruz Biotechnology).

\section{Liquid chromatography-tandem mass spectrometry (LC-MS/MS) analysis}

En-PSCs were treated with phenol red-free and serumfree DMEM-F12 for $48 \mathrm{~h}$, and then, the supernatant was collected. This supernatant was centrifuged at $4000 \times g$ for $20 \mathrm{~min}$ in a concentrating tube (UFC903001, Millipore, Bedford, MA, USA) to obtain concentrated supernatant. Protein in the concentrated supernatant was quantified via BCA Protein Assay (Thermo Fisher Scientific, Rockford, IL, USA). After polyacrylamide gel electrophoresis, Coomassie blue staining was performed, followed by decolorization with a decolorizing solution (10\% Acetic acid, 45\% Methanol, 45\% dd $\mathrm{dd}_{2} \mathrm{O}$ ). Target strips were then cut out and analyzed by LTQ Orbitrap Velos Pro (Thermo Finnigan, CA, USA).

\section{Wound-healing assay}

En-PSCs were treated with phenol red-free and serumfree DMEM-F12 for $48 \mathrm{~h}$, and then, the supernatant was collected. This supernatant was centrifuged at $4000 \times g$ for $20 \mathrm{~min}$ in a concentrating tube (UFC903001, Millipore) to obtain concentrated supernatant. Woundhealing assay was carried out to detect the migration ability of the human endometrial stromal cells (ESCs) cultured with the concentrated supernatant. The percentage of cell migration was analyzed after $24 \mathrm{~h}$ treatment.

\section{Tube formation assays}

First, liquid Matrigel (50 $\mu \mathrm{l})$ (BD Biosciences) was plated per well of a 96-well plate at $4{ }^{\circ} \mathrm{C}$ and was then incubated for $30 \mathrm{~min}$ at $37^{\circ} \mathrm{C}$. Subsequently, human umbilical vein endothelial cells (HUVECs) $\left(1 \times 10^{4} /\right.$ well) suspended in serum-free M199 were added to each well. HUVECs were served as blank control. Vascular endothelial growth factor (VEGF; $0.3 \mathrm{nmol} / \mathrm{L}, 100-20$, Peprotech, Rocky Hill, NJ, USA) was added as positive control. Recombinant human CYR61 (CYR61, C600220005, Sangon Biotech, ShangHai, China) was used at a concentration of $40 \mathrm{ng} / \mathrm{ml}$. Anti-CYR61 antibody (ab24448, Abcam) was added in order to block CYR61. These cells were then incubated for $2 \mathrm{~h}$ at $37^{\circ} \mathrm{C}$, and tube-like structures were photographed with an Olympus digital camera (magnification of $\times 100$ ). The mean number of observed tubes was then counted in three wells, with three to five random fields per well.

\section{Small interfering RNA and plasmid transfection}

When cultured En-PSCs reached 70-80\% confluency, negative control small interfering ribonucleic acid (si-NC, 50 nM, RiboBiO, Guangzhou, China), CYR61-specific small interfering ribonucleic acid (si-CYR61, $50 \mathrm{nM}$, Ribo$\mathrm{BiO}$ ), vector control (GV141, $5 \mu \mathrm{g} / 10^{6}$ cells, GENE CHEM, ShangHai, China), or CYR61 overexpression plasmids (GV141-CYR61, $5 \mu \mathrm{g} / 10^{6}$ cells, GENE CHEM) were transfected into En-PSCs (passage 6) using the Lipofectamine 3000 transfection reagent (L3000075, Invitrogen). En-PSCs were taken as a control group. The transfection efficiency among five groups, including control group, siNC group, si-CYR61 group, vector group, and ov-CYR61 group, was detected after $48 \mathrm{~h}$ by western blotting and ELISA.

\section{Western blotting}

Cells were washed with PBS, and $1 \mathrm{~mL}$ of cell lysis buffer (50.0 mmol/L Tris $\mathrm{pH}=7.6,150.0 \mathrm{mmol} / \mathrm{L} \mathrm{NaCl}, 0.1 \%$ SDS, 1.0\% NP-40, protease inhibitor cocktail) was added. Cells were then scraped on ice, and lysis was allowed to proceed at $4{ }^{\circ} \mathrm{C}$ for $30 \mathrm{~min}$, followed by centrifugation at $15000 \mathrm{rpm}$ for $15 \mathrm{~min}$. Supernatant was then collected, and protein was quantified via BCA. Equal amounts $(30 \mu \mathrm{g})$ of total protein were then subjected to standard Western blotting. Resultant PVDF membranes (Millipore) were probed with primary antibodies against CYR61 (1:500, ab230947, Abcam), $\beta$-actin (1: 10000, AP0060, Bioworld, St Louis Park, MN, USA), or Flag (1: 10000, Sigma). Anti-rabbit IgG (1:10000, A0545, Sigma) was used as a secondary antibody. Detection was performed using an enhanced chemiluminescence kit (Amersham Biosciences Corp., Piscataway, NJ, USA).

\section{In vitro vascular network formation}

Cell culture/co-culture experiments using Matrigel systems were performed to observe the capillary-like network formation. En-PSCs $\left(5 \times 10^{3}\right)$ (above cells transfected for $48 \mathrm{~h}$ ) or HUVECs $\left(5 \times 10^{3}\right)$ were seeded onto Matrigel-coated well and incubated for $2 \mathrm{~h}$. This experiment was divided into five groups including control group, si-NC group, si-CYR61 group, vector group, and ov-CYR61 group. Co-culture of HUVECs with EnPSCs was served as control. Tube-like structures were photographed with an Olympus digital camera (magnification of $\times 100$ ). The mean number of observed tubes was then counted in three wells, with three to five random fields per well.

\section{Transwell migration assays}

Transwell migration assays were divided into six groups including control group, si-NC group, si-CYR61 group, vector group, ov-CYR61 group, and CYR61 group. These experiments were conducted using 24-well plates containing Transwell inserts (Corning Incorporated, $8 \mu \mathrm{m}$, Corning, NY, USA) in vitro [26]. Briefly, En-PSCs $\left(1 \times 10^{6}\right)$ (blank control), transfected En-PSCs, or CYR61 $(40 \mathrm{ng} / \mathrm{ml})$ were added in the lower chamber. Then, 
$1300 \mu \mathrm{l}$ DMEM-F12 containing 10\% FBS was added in the lower chamber, respectively. HUVECs $\left(1 \times 10^{5}\right)$ (passage 3) were resuspended in $200 \mu \mathrm{l}$ serum-free medium and placed in the upper chamber. After co-culture at $37^{\circ} \mathrm{C}$ for $24 \mathrm{~h}$, HUVECs on the membrane were scraped off and the migrating cells under membrane were observed using a microscope. The migrating cells were fixed with methanol and stained with $0.1 \%$ crystal violet for $20 \mathrm{~min}$. The mean number of observed cells was then counted per well, with five random fields per well (magnification of $\times 400$ ).

\section{Elisa}

After $48 \mathrm{~h}$, the supernatant (Phenol red-free medium) of transfected En-PSCs was collected. The supernatant of En-PSCs was served as control. CYR61 levels in the supernatant were measured via an Enzyme-linked immunosorbent assay (EK1203, BOSTER) according to the manufacturer's instructions. The optical density value (OD value) was measured by a microplate reader (Thermo, MA, USA) at $450 \mathrm{~nm}$.

\section{Proliferation assay}

Cell-counting kit-8 (CCK-8) (Dojindo, Kumarmoto, Japan) was used to detect the cell proliferation. After 48 $\mathrm{h}$, these En-PSCs, transfected negative control small interfering ribonucleic acid (si-NC, $50 \mathrm{nM})$, CYR61specific small interfering ribonucleic acid (si-CYR61, 50 $\mathrm{nM}$ ), GV141 control plasmid (vector, $5 \mu \mathrm{g} / 10^{6}$ cells), and GV141-CYR61 overexpression plasmids (ov-CYR61, $5 \mu \mathrm{g} / 10^{6}$ cells) were digested and seeded at $2 \times 10^{3}$ cell per well into 96-cell plates, six parallel wells for each group, which were conventionally cultured in complete medium $(100 \mu \mathrm{l} /$ well $)$ for 1 week.

The CCK- 8 reagent $(10 \mu l)$ was added in phenol redfree medium $(100 \mu \mathrm{l})$ per well. After incubation for $2 \mathrm{~h}$, the optical density value (OD value) was measured at $450 \mathrm{~nm}$ using a microplate reader (Thermo). The growth curve was draw based on the mean value of the eight counts in each group.

\section{Uterine horn injury model and En-PSCs transplantation}

Uterine horn injury model was established according to our previous reports $[6,27,28]$. Briefly, animal experiments were conducted in accordance with the guidelines of the Experimental Animals Management Committee (Jiangsu Province, China). In total, 44 female SpragueDawley (SD) rats $(250-280 \mathrm{~g})$ were purchased from the Animal Model Center of Nanjing Medical University. Vaginal smears were obtained daily between 08:00-10: $00 \mathrm{AM}$. Rats with consecutive 4-day estrous cycles were randomly assigned to five groups, including a shamoperated group (sham; 18 uterine horns), a PBS loaded on a collagen scaffold group (collagen/PBS; 18 uterine horns), an En-PSCs loaded on a collagen scaffold group (collagen/En-PSCs; 18 uterine horns), an En-PSCs with low CYR61 expression loaded on a collagen scaffold group (collagen/si-CYR61 En-PSCs; 16 uterine horns), and an En-PSCs overexpressing CYR61 loaded on a collagen scaffold group (collagen/ov-CYR61 En-PSCs; 18 uterine horns). After rats were anesthetized, uterine horns were exposed via a low abdominal midline incision and a region in the uterine wall of roughly $1.5 \mathrm{~cm}$ in length and $0.5 \mathrm{~cm}$ in width was resected, while the mesometrium side was retained. In the sham group, uterine horns were exposed but not resected. Collagen membrane (ZH-BIO, Yantai, China) was used as an absorbable scaffold material for En-PSCs delivery. The four different kinds of collagen scaffolds (collagen/PBS, collagen/si-CYR61 En-PSCs, collagen/En-PSCs, and collagen/ ov-CYR61 En-PSCs), which were of a dimension matching the resected area, were then sutured into injured area to replace the excised segment. Following completion of the surgery, rats received intramuscular injections of penicillin twice a day for 3 days.

\section{Histological analysis}

On days 30 and 90 post-transplantation, a subset of rats ( $n=4$ uterine horns) from each group was euthanized. The injured site of each uterine horn was dissected, fixed in neutral formaldehyde for $24 \mathrm{~h}$, and embedded in paraffin perpendicularly. Sections $(3 \mu \mathrm{m})$ of uterine horns were then prepared transversally.

Hematoxylin and eosin (H\&E) staining was then employed to observe tissue structure. Sections were stained for immunohistochemistry with anti- $\alpha$-smooth muscle actin antibody ( $\alpha$-SMA, 1:1500, ab5694, Abcam) and anti-von Willebrand factor antibody (vWF; 1:10000, ab6994, Abcam). The thickness of endometrium was measured using ImageJ (National Institutes of Health, USA). The percentage of $\alpha$-SMA positive area ( $\alpha$-SMA positive area of the injured region/total $\alpha$-SMA positive area) was used to evaluate smooth muscle abundance with the Image-Pro Plus software (Media Cybernetics, Inc., Rockville, MD, USA). Blood vessel density was evaluated in at least three randomly selected fields per section under a magnification of $\times 400$ [6].

\section{Fertility test}

Fertility testing was employed to assess the function of the injured uteri, to determine whether they were receptive to fertilized ova and to assess whether they were able to support embryos to a late stage of pregnancy. Ninety days post-surgery, rats in estrus $(n=8$ uterine horns for the collagen/si-CYR61 En-PSCs group, and $n=10$ uterine horns for the sham group, the collagen/ PBS group, the collagen/En-PSCs group, the collagen/siCYR61 En-PSCs group, or collagen/ov-CYR61 En-PSCs 

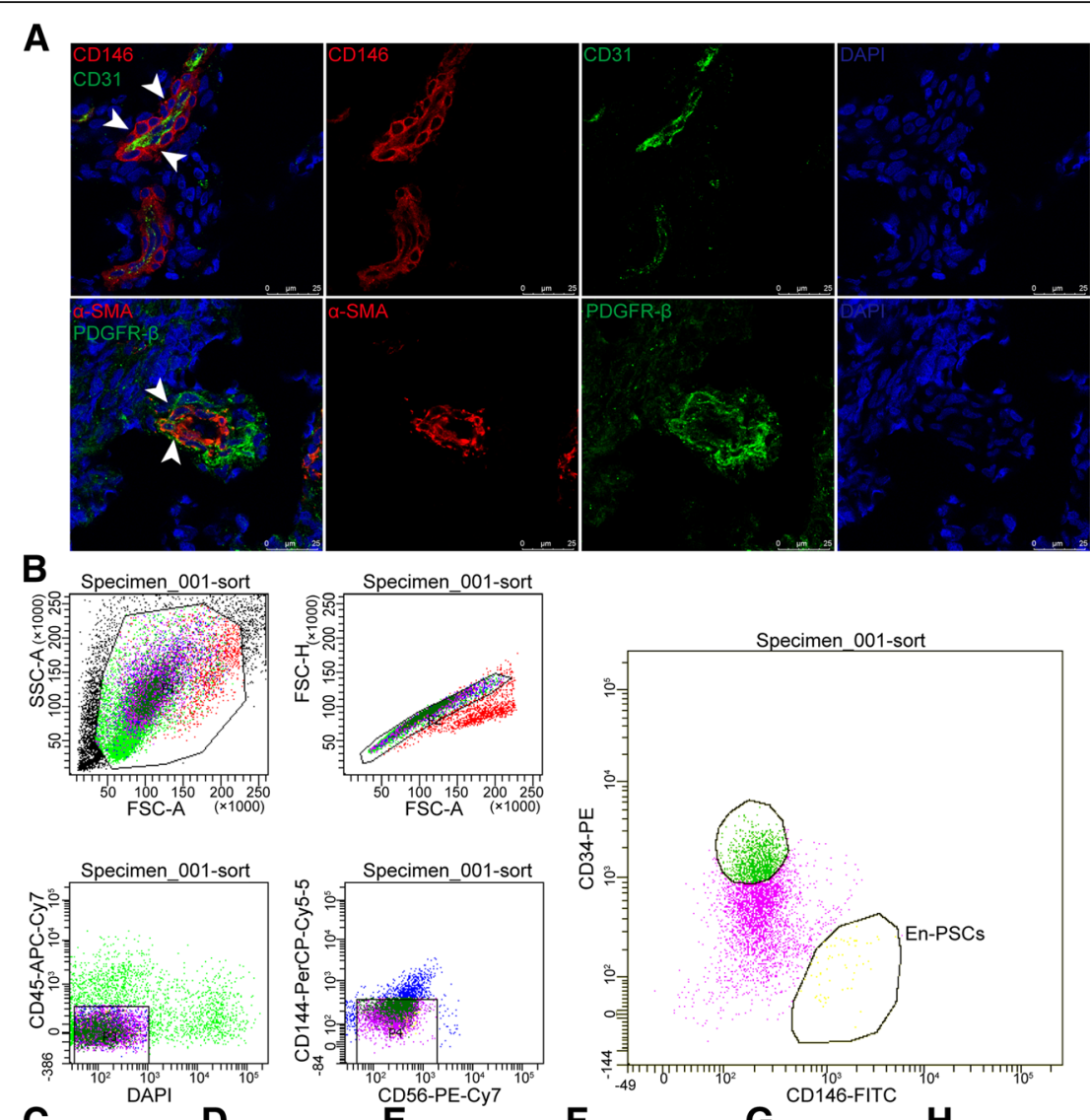

C
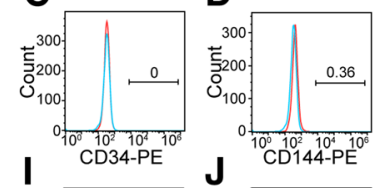

ED
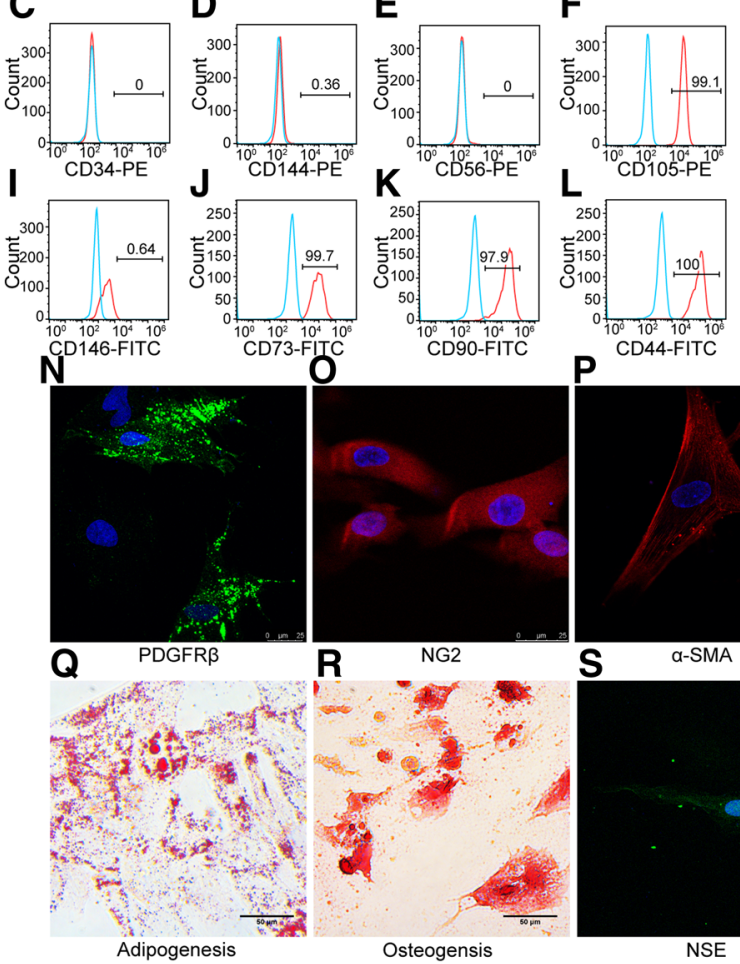

G
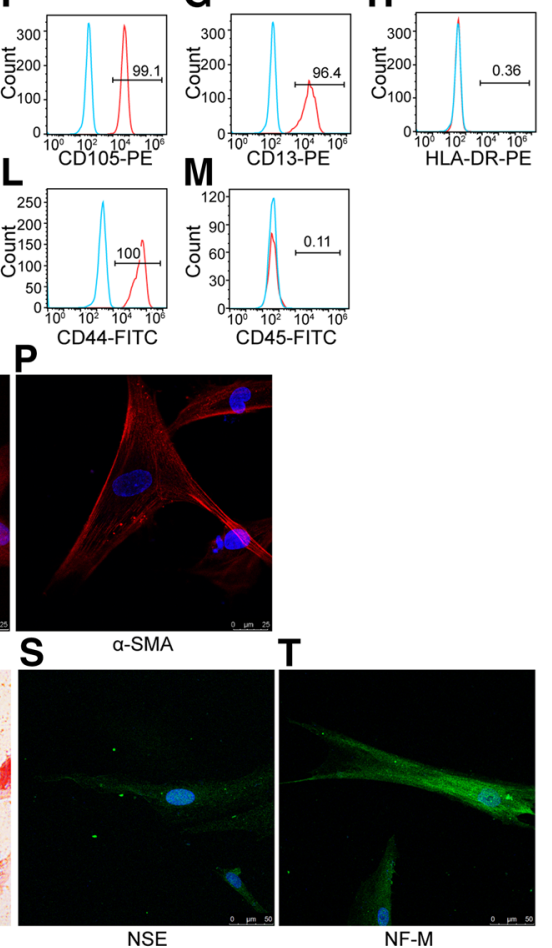

Fig. 1 (See legend on next page.) 
(See figure on previous page.)

Fig. 1 Phenotype and multidirectional differentiation potential of En-PSCs. a Immunofluorescence staining in human endometrium displayed CD146, CD31, PDGFRß, and a-SMA. The arrow showed En-PSCs. Scale bars, 25 mm. b En-PSCs (CD146+CD34-CD45-CD56-CD144-) were sorted by flow cytometry. $\mathbf{c}-\mathbf{m}$ Flow cytometry analysis of immune-markers in En-PSCs. $\mathbf{n}-\mathbf{p}$ En-PSCs expressed PDGFR , NG2, and a-SMA. Scale bars, $25 \mu \mathrm{m}$. q Intracellular lipid droplet induced from En-PSCs were detected by Oil red O staining. Scale bars, $50 \mu \mathrm{m}$. $\mathbf{r}$ Calcified nodule stained with Alizarin red S indicated that En-PSCs differentiated to osteogenic lineage. Scale bars, $50 \mu \mathrm{m}$. Neural-like differentiation was confirmed by immunofluorescence staining with anti-NSE antibody (s) and anti-NF-M antibody (t). Scale bars, $50 \mu \mathrm{m}$

group) were mated with 10-week-old fertile male Sprague-Dawley rats. Day 0 of pregnancy was defined as the day a vaginal plug was found. Rats were then euthanized on gestation day 15-19, and uterine horns were examined for the presence of embryos.

\section{Statistical analysis}

Data were present as means \pm S.E.M. and were analyzed using IBM SPSS Statistics Package for Social Science (Version 22.0, IBM Corp., Armonk, NY, USA). Multiple group comparisons were determined by one-way ANOVA. The pregnancy rates were presented as count and percentage, and multiple group comparisons were analyzed by Fisher exact test followed by Bonferroni correction. $P<0.05$ was the threshold of statistical significance.

\section{Results}

\section{Human endometrial En-PSCs phenotypes}

CD146, PDGFR $\beta$, and $\alpha$-SMA are the markers of perivascular cells, and CD31 is used to identify endothelial cells [29]. En-PSCs were detected around the blood vessels in human endometrium (Fig. 1a). Then, En-PSCs (CD146+CD34-CD45-CD56-CD144-) were sorted by flow cytometry from endometrial tissue samples (Fig. 1b). Percentage of immunophenotype in En-PSCs at passage 6 for CD34 was 0\% (Fig. 1c), for CD144 was 0.36\% (Fig. 1d), for CD56 was 0\% (Fig. 1e), for CD105 was $99.1 \%$ (Fig. 1f), for CD13 was $96.4 \%$ (Fig. 1g), for HLA-DR was $0.36 \%$ (Fig. 1h), for CD146 was $64 \%$ (Fig. 1i), for CD73 was 99.7\% (Fig. 1j), for CD90 was 97.9\% (Fig. 1k), for CD44 was 100\% (Fig. 1l), and for CD45 was $0.11 \%$ (Fig. $1 \mathrm{~m}$ ). These were consistent with previous reports of MSCs surface markers [28]. Cultured En-PSCs at passage 6 expressed PDGFR $\beta$ (Fig. 1n), NG2 (Fig. 1o), and $\alpha$-SMA (Fig. 1p).

\section{Assessment of En-PSCs multipotency}

To assess whether these isolated En-PSCs were capable of multilineage differentiation, the cells grown to passage 6 were cultured in media formulated to induce adipogenesis, osteogenesis, or neural-like differentiation. For adipogenesis, lipid droplets were detected by oil red $\mathrm{O}$ staining on day 30 (Fig. 1q). For osteogenesis, bone nodules were detected by alizarin red $\mathrm{S}$ staining on day 30 (Fig. 1r). Neural-like differentiation was confirmed by NSE (Fig. 1s) and NF-M (Fig. 1t) via immunofluorescence staining.
These results suggested that En-PSCs had multilineage differentiation potential.

\section{Human En-PSCs secrete angiogenesis-related factors}

A mass spectrometry analysis revealed En-PSCs secrete multiple pro-angiogenic factors, as well as CYR61 (Table 1) . A total of 929 proteins were identified by mass spectrometry. A GO Functional Annotation Clustering analysis via DAVID 6.8 online (https://david.ncifcrf.gov/) suggested that there were 203 secreted proteins (Additional file 3: Table S3) among these identified proteins. These 203 secreted proteins were compared with 781 proteins known to be associated with angiogenesis (Human sapiens) in the Uniprot Online Protein Library (https://www.uniprot. org/), of which 38 total angiogenesis-related proteins were identified (Table 1).

\section{En-PSCs with different CYR61 levels show different capacity for angiogenesis}

The role of CYR61 in angiogenesis was evaluated via a tube formation assay and an antibody blocking test. As shown in Fig. 2a, b, the number of tubes per field in wells treated with human recombinant CYR61 protein $(23.500 \pm 1.727)$ was significantly higher than that in control wells $(16.830 \pm 1.195)(P<0.01)$ or in the group which received a CYR61 blocking antibody (2.667 \pm 0.843) $(P<0.0001)$. Interestingly, the number of tubes per field in CYR61 blocking group was significantly lower than in the control group $(P<0.0001)$.

After transfection, different expression levels of CYR61 were confirmed in En-PSCs by Western Blotting (Additional file 1: Figure S1A). Secreted CYR61 levels were also measured in the culture supernatant by ELISA (Fig. 2c). CYR61 levels in the supernatant of the ovCYR61 group $(2442 \pm 41.64 \mathrm{pg} / \mathrm{ml})$ was nearly twice that of the control group $(1127 \pm 81.25 \mathrm{pg} / \mathrm{ml})(P<0.0001)$. The concentration of CYR61 in the si-CYR61 group $(851.6 \pm 57.03 \mathrm{pg} / \mathrm{ml})$ was lower than that in the control group $(P<0.05)$.

Furthermore, CCK-8 assay was also performed to measure the differences of proliferative capability in control group, si-NC group, si-CYR61 group, vector group, and ov-CYR61 group, but no significant differences were observed (Additional file 1: Figure S1B). As shown in Fig. 2d, in vascular network formation assays in vitro, the number of tubes per field in the ov-CYR61 group 
Table 1 Angiogenesis-related protein in En-PSCs supernatant

\begin{tabular}{|c|c|c|c|c|}
\hline Accession & Score & Content & Protein name & Function \\
\hline P09486 & 618 & 12.3 & $\mathrm{BM}-40$ & Negative regulation of Angiogenesis \\
\hline P08253 & 3054 & 12.09 & MMP-2 & Angiogenesis \\
\hline Q15582 & 1967 & 11.4 & Beta ig-h3 & Angiogenesis \\
\hline P05121 & 1157 & 5.75 & Plasminogen activator inhibitor 1 & Angiogenesis \\
\hline P07355 & 712 & 5.56 & Annexin A2 & Angiogenesis \\
\hline P02751 & 5713 & 5.14 & Fibronectin & Angiogenesis \\
\hline P36955 & 985 & 3.22 & PEDF & Negative regulation of angiogenesis \\
\hline P08572 & 2285 & 2.9 & Collagen alpha-2(IV) chain & Angiogenesis \\
\hline Q16610 & 723 & 2.62 & Extracellular matrix protein 1 & Angiogenesis \\
\hline P07585 & 385 & 2.04 & Decorin & Negative regulation of angiogenesis \\
\hline O60565 & 229 & 1.8 & Gremlin-1 & Cell migration involved in sprouting angiogenesis \\
\hline Q99969 & 150 & 1.67 & Retinoic acid receptor responder protein 2 & Angiogenesis \\
\hline P04083 & 372 & 1.66 & Annexin A1 & Positive regulation of cell migration involved in sprouting angiogenesis \\
\hline Q08431 & 310 & 1.39 & MFGM & Angiogenesis \\
\hline Q92743 & 269 & 1.22 & Serine protease HTRA1 & Angiogenesis \\
\hline P27658 & 197 & 0.93 & Collagen alpha-1(VIII) chain & Angiogenesis \\
\hline Q969H8 & 117 & 0.93 & MYDGF & Angiogenesis \\
\hline Q9Y6C2 & 540 & 0.93 & EMILIN-1 & Negative regulation of angiogenesis \\
\hline Q9Y4K0 & 445 & 0.79 & Lysyl oxidase homolog 2 & Angiogenesis \\
\hline P31151 & 92 & 0.69 & Protein S100-A7 & Angiogenesis \\
\hline P02462 & 682 & 0.55 & Collagen alpha-1(IV) chain & Blood vessel morphogenesis \\
\hline Q15389 & 204 & 0.47 & ANG-1 & Sprouting angiogenesis \\
\hline 015230 & 1412 & 0.36 & Laminin subunit alpha-5 & Angiogenesis \\
\hline E9PEP6 & 196 & 0.29 & Neuropilin & Angiogenesis \\
\hline P98160 & 1080 & 0.23 & HSPG & Angiogenesis \\
\hline O60687 & 119 & 0.19 & Sushi repeat-containing protein SRPX2 & Angiogenesis \\
\hline P29279 & 76 & 0.17 & CTGF & Angiogenesis \\
\hline 000622 & 95 & 0.16 & CYR61 & Intussusceptive angiogenesis, wound healing, spreading of cells \\
\hline Q14118 & 109 & 0.14 & Dystroglycan & Angiogenesis involved in wound healing \\
\hline Q13443 & 58 & 0.11 & ADAM 9 & Angiogenesis \\
\hline P39060 & 209 & 0.09 & Collagen alpha-1(XVIII) chain & Angiogenesis \\
\hline P36222 & 33 & 0.08 & Chitinase-3-like protein 1 & Positive regulation of angiogenesis \\
\hline Q9GZP0 & 99 & 0.08 & PDGF-D & Angiogenesis \\
\hline P01024 & 73 & 0.07 & Complement C3 & Positive regulation of angiogenesis \\
\hline 015123 & 34 & 0.06 & ANG-2 & Angiogenesis \\
\hline O60462 & 32 & 0.06 & Neuropilin-2 & Angiogenesis \\
\hline Q12884 & 38 & 0.04 & Prolyl endopeptidase FAP & Angiogenesis \\
\hline
\end{tabular}

MMP1 matrix metalloproteinase 1, ANG-1 angiopoietin-1, Beta ig-h3 transforming growth factor-beta-induced protein ig-h3, PDGF-D platelet-derived growth factor $D, C T G F$ connective tissue growth factor

$(18.67 \pm 2.472)$ was larger than that in the si-CYR61 group $(5.833 \pm 3.807)(P<0.001)$. The number of tubes per field in si-NC group $(13.17 \pm 0.792)$ was also larger than that in si-CYR61 group $(P<0.001)$. In a migration assay (Fig. 2e), the number of cells per field in the ov-
CYR61 group (39 \pm 1.703$)$ was greater than that in the si-CYR61 group $(19.6 \pm 2.015)(P<0.0001)$ or the control group $(26.4 \pm 1.218)(P<0.001)$. Additionally, the number of cells per field in the control group was greater than that in the si-CYR61 group $(P<0.05)$. 
A

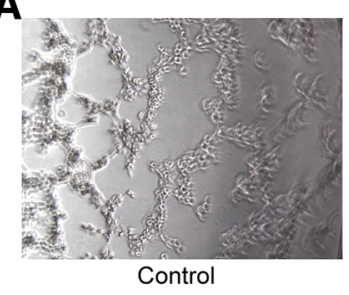

B

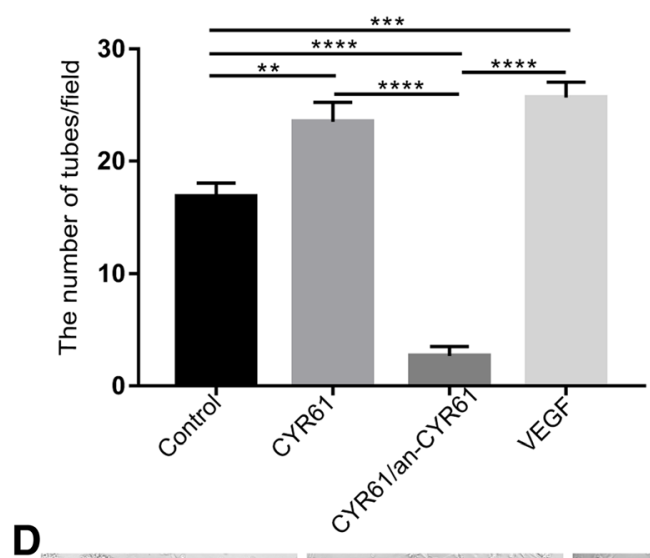

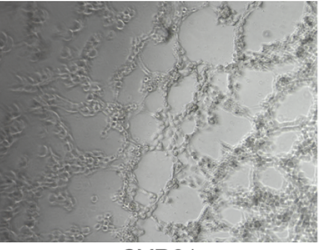

CYR61

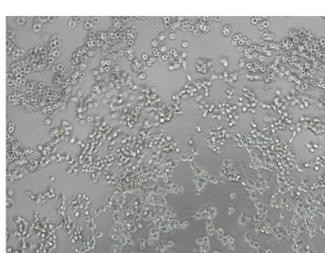

CYR61/Anti-CYR61

C

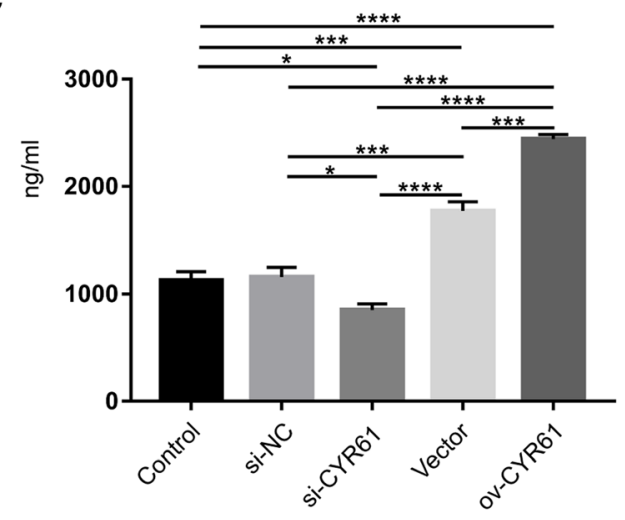

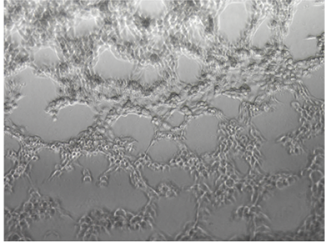

VEGF

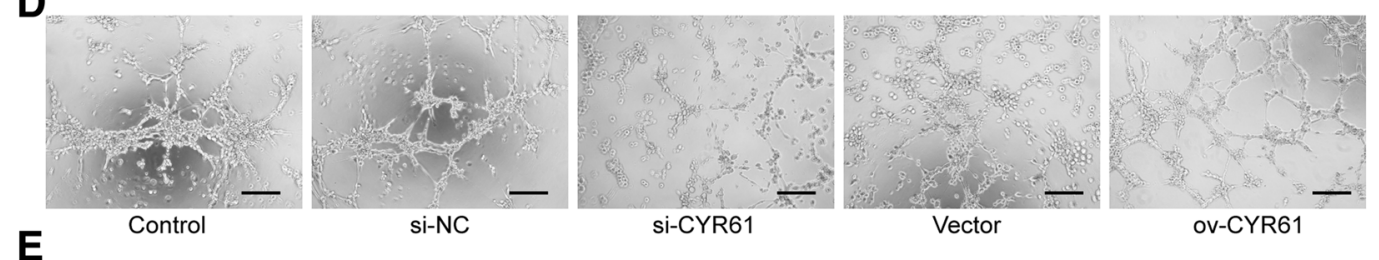

E

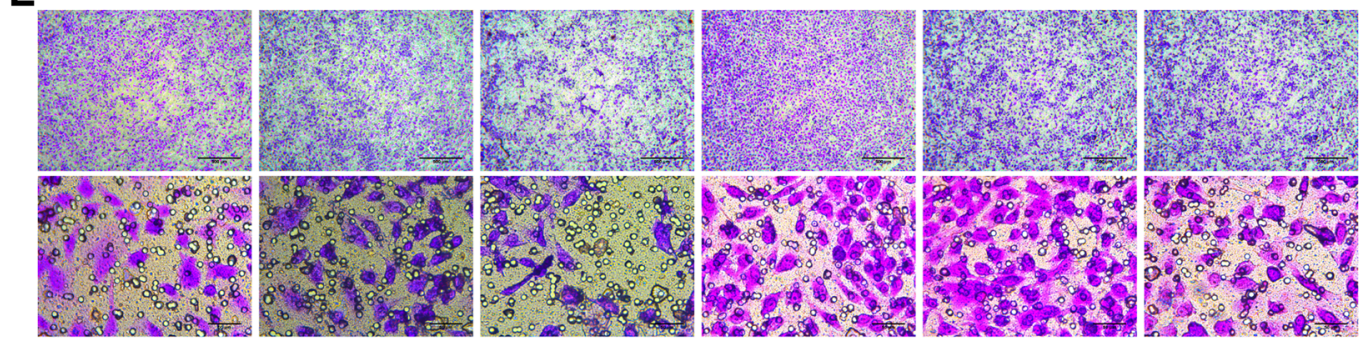

$\mathbf{F}$

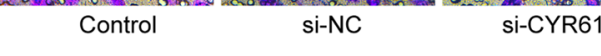

G

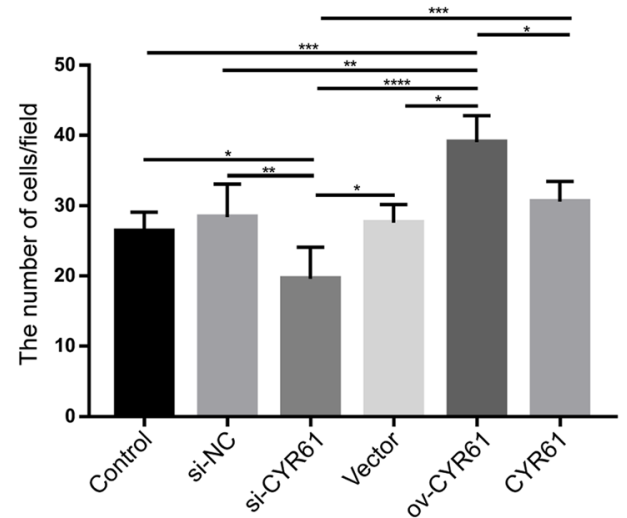

Fig. 2 (See legend on next page.) 
(See figure on previous page.)

Fig. 2 En-PSCs with elevated CYR61 expression induce angiogenesis. a The tube formation after treatment with CYR61 alone, combined CYR61\&AntiCYR61, VEGF alone, were microscopically compared. $\mathbf{b}$ The mean number of observed tubes was counted in three wells, with three to five random fields per well. c ELISA were performed $48 \mathrm{~h}$ after transfection of si-CYR61 or ov-CYR61. The concentration of CYR61 was measured in the supernatant of transfected En-PSCs. $\mathbf{d}$ Tube formation assays were performed $48 \mathrm{~h}$ after transfection of si-CYR61 or ov-CYR61. The tube formation after co-culture of HUVECs with transfected En-PSCs were microscopically compared. $\mathbf{f}$ The mean number of observed tubes was counted in three wells, with three to five random fields per well. Scale bars, $200 \mu \mathrm{m}$. e Effect of transfected En-PSCs on HUVECs migration. The HUVECs migrated to the bottom of the transwell membrane were stained with crystal violet. Scale bars, $500 \mu \mathrm{m}$. Local magnification of figures were showed in the pictures below. Scale bar, $50 \mu \mathrm{m} . \mathbf{g}$ The mean number of observed cells was then counted per well, with five random fields per well (magnification of $\times 400$ ). Each experiment was repeated three times. Data were presented as mean \pm SEM. ${ }^{*} P<0.05,{ }^{* *} P<0.01,{ }^{* *} P<0.001$, and ${ }^{* * * *} P<0.0001$

\section{Utilizing En-PSCs for the treatment of full-thickness uterine injury}

At 30 days after surgical treatment, collagen scaffolds implanted into rats had been degraded. We found that the morphology and blood supply of rat uterine tissue in the collagen/ov-CYR61 En-PSCs group were better than those in the collagen/si-CYR61 En-PSCs group or the collagen/PBS group (Additional file 2: Figure S2).

Hematoxylin-eosin staining was next used to measure the endometrial thickness at the injury uterine sites. After 30 days of repair, relative to the collagen/PBS group, endometrial morphology was more complete in the three cell treatment groups (Fig. 3C-E, $C^{\prime}-E^{\prime}$ ). Endometrial thickness in the collagen/ov-CYR61 EnPSCs group $(418.076 \pm 15.685 \mu \mathrm{m})$ was greater than that in the collagen/PBS group $(188.798 \pm 25.703 \mu \mathrm{m})(P<$ $0.0001)$, the collagen/En-PSCs group $(327.594 \pm 22.990 \mu \mathrm{m})$ $(P<0.01)$, or the collagen/si-CYR61 En-PSCs group $(203.755 \pm 10.246 \mu \mathrm{m})(P<0.0001)$ (Fig. 3K). In addition, endometrial thickness in the collagen/En-PSCs group was thicker than in the collagen/PBS group $(P<0.001)$ or the siCYR61 En-PSCs group $(P<0.001)$ (Fig. 3K). After 90 days, endometrial thickness in the collagen/ov-CYR61 En-PSCs group $(456.075 \pm 26.535 \mu \mathrm{m})$ (Fig. 3J, J') was greater than that in the collagen/PBS group $(281.459 \pm 35.876 \mu \mathrm{m})(P<$ $0.0001)$, the collagen/En-PSCs group $(302.211 \pm 12.466 \mu \mathrm{m})$ $(P<0.0001)$, or the collagen/si-CYR61 En-PSCs group $(202.956 \pm 10.095 \mu \mathrm{m})(P<0.0001)$ (Fig. 3K). Indeed, EnPSC supernatant promote the migration of endometrial stromal cells (ESCs) in vitro (Additional file 1: Figure $\mathrm{S} 1 \mathrm{C})$, although there was no significant difference in the proliferation of ESCs in En-PSCs supernatant (Additional file 1: Figure S1E).

Uterine smooth muscle bundles at the injured site in rats from each group were detected by a-SMA antibody staining. At 30 days after treatment, relative to the collagen/PBS group, the smooth muscle in the collagen/ovCYR61 En-PSCs group was more regular (Fig. 4E, E'). The percentage of a-SMA-positive area in the collagen/ ov-CYR61 En-PSCs group $(17.810 \% \pm 3.246 \%)$ was higher than that in the collagen/PBS group $(5.332 \% \pm$ $1.614 \%)(P<0.05)$ or the collagen/si-CYR61 En-PSCs group $(5.561 \% \pm 0.807 \%)(P<0.05)$ (Fig. $4 \mathrm{~K})$. At 90 days after treatment, the percentage of a-SMA-positive area in the collagen/ov-CYR61 En-PSCs group $(22.062 \% \pm$ $2.806 \%)$ was higher than that in the collagen/si-CYR61 En-PSCs group $(9.066 \% \pm 2.020 \%)(P<0.01)$ (Fig. $4 \mathrm{~K})$.

At 30 days after treatment, compared with the collagen/PBS group and the collagen/si-CYR61 En-PSCs group, the collagen/ov-CYR61 En-PSCs group induced more blood vessels and these vessels were more evenly distributed (Fig. 5E, E'). The density of blood vessels in the collagen/ov-CYR61 En-PSCs group $(9.667 \pm 0.482)$ was greater than that in the collagen/PBS group $(4.111 \pm 0.261) \quad(P<0.0001)$ or the collagen/si-CYR61 En-PSCs group $(3.333 \pm 0.707)(P<0.0001)$ (Fig. 5K). At 90 days after treatment, the distribution of blood vessels in the collagen/ov-CYR61 En-PSCs group (Fig. 5J, J') was similar to that in the sham group (Fig. 5F, F'), the blood vessel distribution in the collagen/PBS group (Fig. 5G, G') was disordered, and in the collagen/siCYR61 En-PSCs group (Fig. 5I, I'), there were few blood vessels. Blood vessel density in the collagen/ov-CYR61 En-PSCs group $(11.667 \pm 1.287)$ was greater than that in the collagen/En-PSCs group $(7.167 \pm 0.672)(P<0.05)$ or the collagen/si-CYR61 En-PSCs group $(3.750 \pm 0.906)$ $(P<0.0001)$ (Fig. 5K).

\section{Regenerated uterine fertility assessment}

At 90 days after surgical treatment, a fertility assessment revealed the presence of viable embryos in some of the regenerated uteri (Fig. 6). Indeed, pregnancy rates (Table 2) were $100 \%$ in the sham group, $40 \%$ in the collagen/PBS group, $80 \%$ in the collagen/En-PSCs group, $12.5 \%$ in the collagen/si-CYR61 En-PSCs group, and $80 \%$ in the collagen/ov-CYR61 En-PSCs group. At the injured site, there were no embryos evident in rats of the collagen/PBS group, two embryos in the collagen/EnPSCs group, one embryo in the collagen/si-CYR61 EnPSCs group, and four embryos in the collagen/ovCYR61 En-PSCs group.

\section{Discussion}

Tissue repair often requires angiogenesis to support tissue vascularization and regeneration [30]. The present study suggested that collagen/ov-CYR61 En-PSCs induced angiogenesis and improved the repair of fullthickness uterine injury in rats, restoring both structure 


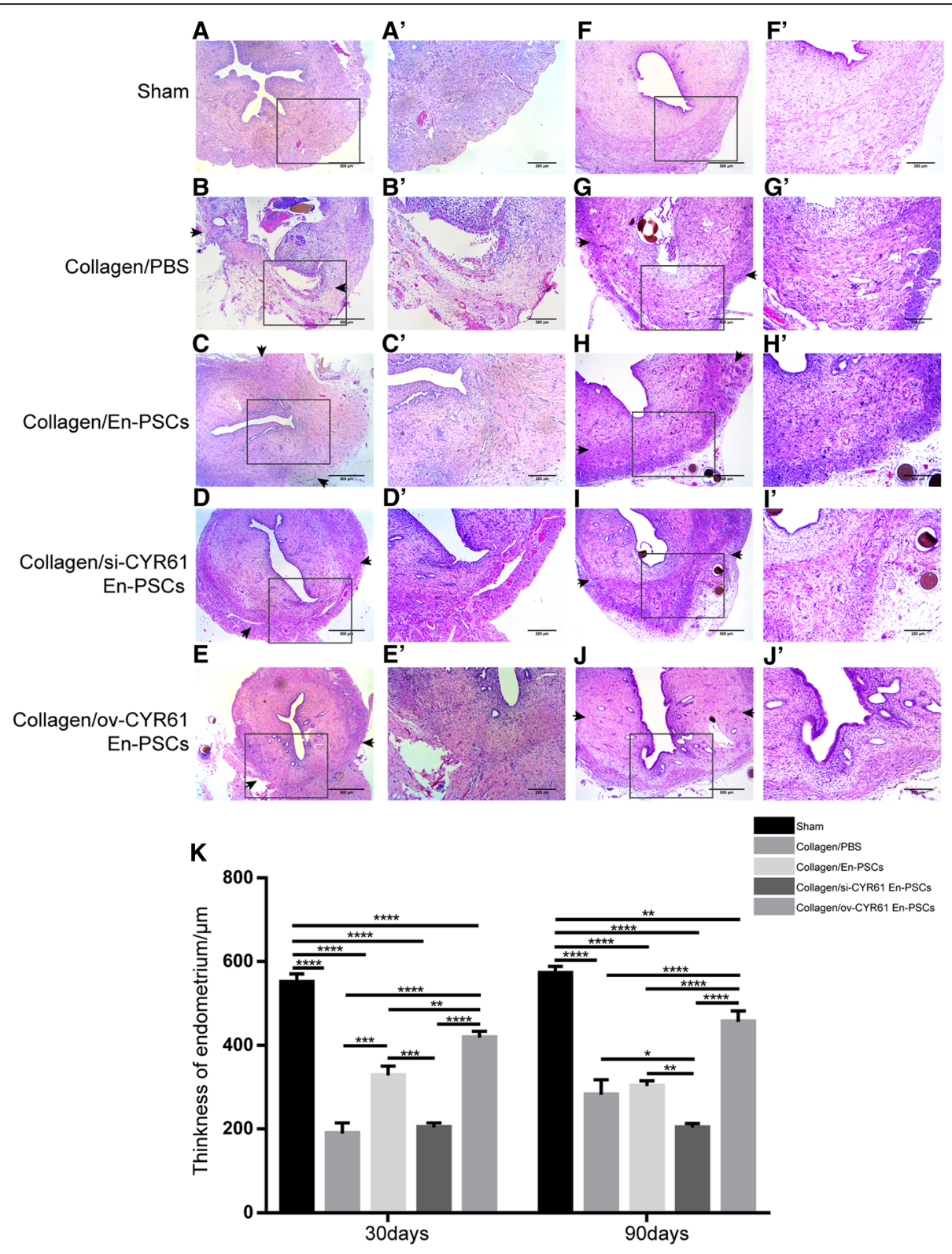

Fig. 3 The regenerative uterine horns after collagen/transfected En-PSCs transplantation. Histological structures of the regenerative uterine horns at 30 days $(\mathbf{A}-\mathbf{E})$ and 90 days $(\mathbf{F}-\mathbf{J})$ in sham group $(\mathbf{A}$ and $\mathbf{F})$, collagen/PBS group (B and $\mathbf{G})$, collagen/En-PSCs group (C and $\mathbf{H})$, collagen/si-CYR61 EnPSCs group (D and $\mathbf{I}$ ), and collagen/ov-CYR61 En-PSCs group (E and $\mathbf{J})$. Arrowheads indicated repair sites. Scale bar, $500 \mu \mathrm{mm}$. Local magnification of figures $(\mathbf{A}-\mathbf{J})$ were showed in the pictures $\left(\mathbf{A}^{\prime}-\mathbf{J}^{\prime}\right)$. Scale bar, $200 \mu \mathrm{m}$. $\mathbf{K}$ Statistical analysis of the thickness of endometrium in the five groups. Each experiment was repeated four times. Data were presented as mean $\pm \mathrm{SEM}$. ${ }^{*} P<0.05$, ${ }^{* *} P<0.01,{ }^{* * *} P<0.001$, and ${ }^{* * * *} P<0.0001$

and function of injured uteri. These genetically modified En-PSCs might provide the new knowledge for endometrial regeneration.

MSCs express specific markers like CD73, CD90, and CD105 and were negative for hematopoietic markers such as CD34, CD45, and HLA-DR [29]. Simultaneously, they possess multipotency differentiating in vitro into adipocytes [19], osteoblasts, chondrocytes [31], phagocytes, and granulocytes [19]. CD146+PDGFR $\beta+$ human endometrial cells are a small population of MSC-like cells that may be responsible for endometrial cyclical growth, named as eMSCs [10]. In the present study, sorted En-PSCs (CD146+CD34-CD45-CD56-CD144-) not only expressed MSCs markers but also possessed multilineage differentiation potency. En-PSCs expressing PDGFR $\beta$ may be one subset of eMSCs. Firstly, the proliferation rate of eMSCs is greater than that of bone marrow-derived and dental pulp stem cells [32] and stem cells derived from umbilical cord [33]. Secondly, eMSCs show superior immunomodulatory effect compared with bone marrow-derived stem cells 


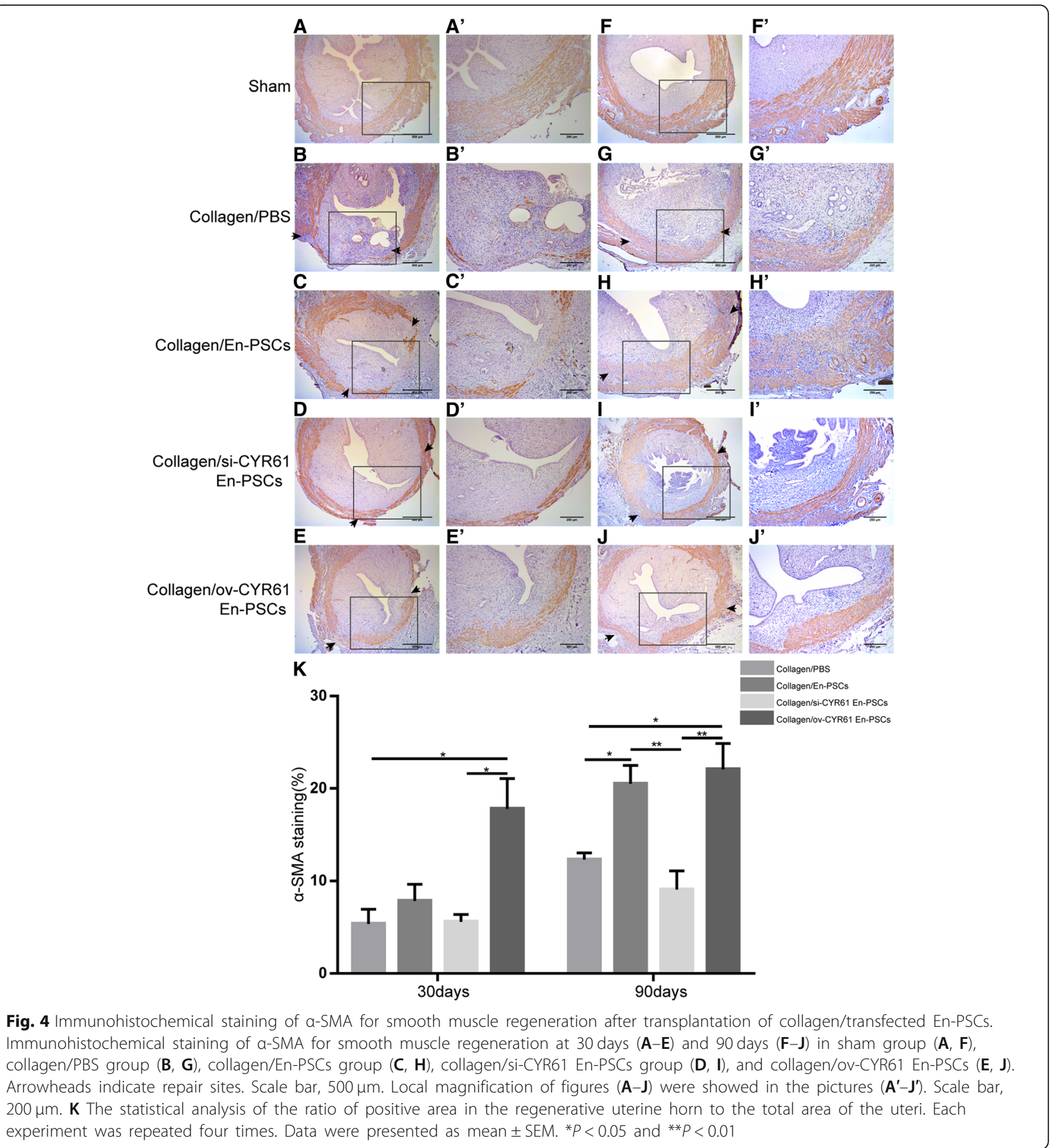

[34]. Thirdly, En-PSCs expressing PDGFR $\beta$, NG2, and $\alpha-$ SMA, as perivascular cells, are able to maintain endothelial tube networks and improve angiogenic sprouting in vitro [19].

In response to injury, MSCs secrete large quantities of cytokines that are promoting angiogenesis, supporting of growth and differentiation of local cells and anti-scarring to regenerate the tissues [35]. LC-MS/MS identified that En-PSCs secreted angiogenesis-related factors such as connective tissue growth factor (CTGF), Angiopoietin-1 (Ang1), and CYR61. CTGF-null mice show defects in angiogenesis, with impaired interaction between endothelial cells and perivascular cells and collagen IV deficiency in the endothelial basement membrane [36]. Previous study showed prominent defects in endocardial and myocardial development as well as a less complex vascular network in mice embryos were observed in a knockout model of ANGPT1 [37, 38]. Due to severe 


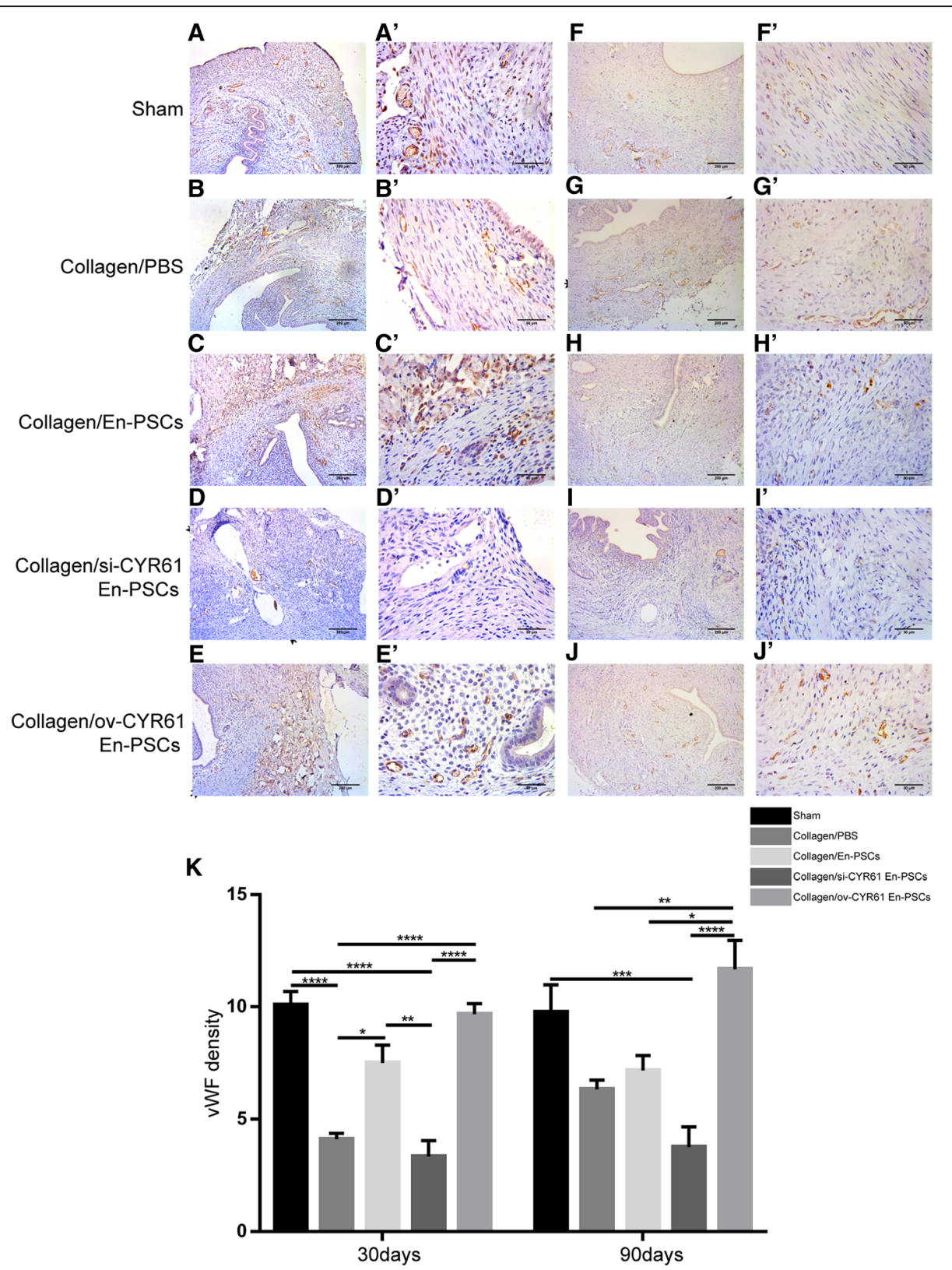

Fig. 5 Immunohistochemical staining of VWF in the newly regenerated uteri after transplantation of collagen/transfected En-PSCs. Detection of VWF expression for blood vessels in the regenerated uteri at days 30 days $(\mathbf{A}-\mathbf{E})$ and 90 days $(\mathbf{F}-\mathbf{I})$ in sham group $(\mathbf{A}, \mathbf{F})$, collagen/PBS group (B, G), collagen/si-CYR61 En-PSCs group (C, H), collagen/vector En-PSCs group (D, I), and collagen/ov-CYR61 En-PSCs group (E, J). Arrowheads indicate repair site. Scale bar, $500 \mu \mathrm{m}$. Local magnification of figures $(\mathbf{A}-\mathbf{J})$ were showed in the pictures ( $\mathbf{A}^{\prime}-\mathbf{J} \mathbf{J}^{\prime}$ ). Scale bar, $50 \mu \mathrm{m}$. $\mathbf{K}$ The statistical analysis of the capillary vessels number from at least three randomly selected fields under a magnification of 400 . Each experiment was repeated four times. Data were presented as mean \pm SEM. ${ }^{*} P<0.05,{ }^{* *} P<0.01$, ${ }^{* *} P<0.001$, and ${ }^{* * *} P<0.0001$

defects in cardiac perivalvular morphogenesis, impaired placentation, and loss of vascular integrity, CYR61-null mice are embryonic lethal [21, 39]. CYR61 binds to integrin $\alpha v \beta 3$ to support endothelial cell adhesion [40]. Moreover, CYR61 regulates Dll4 expression, Dll-Notch signaling, and vascular endothelial growth factor receptor 2 (VEGFR2) signaling, thus regulating the interaction between tip and stalk cells to form the endothelial lumen of the vessel [41-43]. Furthermore, CYR61 induces IL-6 expression in macrophages through integrin $\alpha M \beta 2$ and promotes intestinal epithelial cell proliferation in fibroblasts through $\alpha 6 \beta 1$ [44]. The present study found that CYR61 promote HUVECs to form tubes while inhibition of CYR61 can inhibit tube formation. As expected, EnPSCs were higher in promoting migration than si-NC En-PSCs and lower than ov-CYR61 En-PSCs. CYR61 


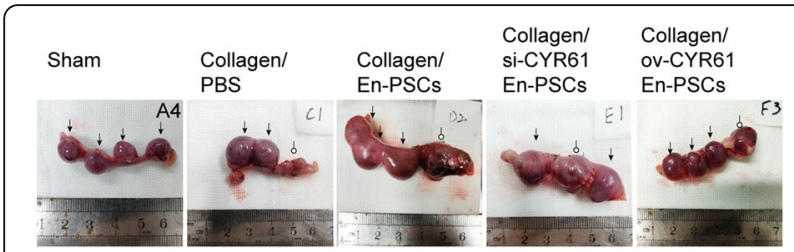

Fig. 6 Embryos implantation of different groups after transplantation of collagen/transfected En-PSCs. Pregnancies of different groups at 90 days postoperative in sham group, collagen/PBS and collagen/EnPSCs group, collagen/si-CYR61 En-PSCs, and collagen/ov-En-PSCs. Hollow circle arrows indicated embryos implanted in the injured site. Black arrows showed embryos in the normal tissue

content in En-PSCs supernatant was higher than siCYR61 En-PSCs and lower than ov-CYR61 En-PSCs. In vivo study showed that ov-CYR61 En-PSCs induced increased expression of vWF and promote endometrial repair compared with En-PSCs. Therefore, different angiogenic properties of En-PSCs, si-CYR61 En-PSCs, and ov-CYR61 En-PSCs can be explained by different levels of expression of CYR61 in these cells. We also detected the presence of $\alpha v \beta 3$ as a potential factor relevant to angiogenesis (data not shown) and hypothesized that CYR61/ $\alpha \beta 33$ was an important pathway for the angiogenic process. However, the present data is not enough to explain the molecular mechanism in occurrence of uterine neovascularization. Further studies will be needed to fully clarify the mechanism of angiogenesis induced by CYR61 secreted by En-PSCs in uteri.

In tissue engineering, selection of a suitable source of stem cells is highly important for regeneration. Functional regeneration of injured rat uteri has been realized by transplantation of human basic fibroblast growth factor, bone marrow mesenchymal stem cells, or umbilical cord-derived mesenchymal stem cells with collagen

Table 2 Reproductive outcomes comparison among different treatments for 90 days after uterine injury

\begin{tabular}{lllll}
\hline Variable & $\begin{array}{l}\text { Total number } \\
\text { of uterine } \\
\text { horns }\end{array}$ & $\begin{array}{l}\text { Non-pregnant } \\
\text { uterine horns } \\
(\%)\end{array}$ & $\begin{array}{l}\text { Pregnant } \\
\text { uterine } \\
\text { horns (\%) }\end{array}$ & $\begin{array}{l}\text { Uterine horns } \\
\text { with embryo } \\
\text { implantation on } \\
\text { the scar site (\%) }\end{array}$ \\
\hline Sham & 10 & 0 & $10(100)$ & \\
Collagen/PBS & 10 & $6(60)$ & $4(40)$ & $0(0)$ \\
$\begin{array}{l}\text { Collagen/ } \\
\text { En-PSCs }\end{array}$ & 10 & $2(20)$ & $8(80)$ & $2(20)$ \\
$\begin{array}{l}\text { Collagen/ } \\
\text { Si-CYR61 }\end{array}$ & 8 & $7(87.5)$ & $1(12.5)$ & $1(12.5)$ \\
En-PSCs & & & & \\
$\begin{array}{l}\text { Collagen/ } \\
\text { ov-CYR61 }\end{array}$ & 10 & $2(20)$ & $8(80)$ & $4(40)$ \\
En-PSCs & & & \\
$P$ value & & & & \\
\hline
\end{tabular}

a Each rat has two uterine horns

${ }^{b}$ Bonferroni correction: critical level of significance, $p<0.008$. There was no statistical difference between two groups scaffolds [6, 27, 28]. A suitable cell source must have the following characteristics and advantages: not carrying the risk of disease transmission, inducing angiogenesis, not triggering host immune, and producing an extracellular matrix [45, 46]. Hence, genetically modified EnPSCs are expected to be used successfully in endometrial tissue regeneration.

\section{Conclusions}

In the present study, it has been identified that En-PSCs induce angiogenesis via CYR61. The current data highlight the importance of collagen/ov-CYR61 En-PSCs system, promoting regeneration of endometrium and myometrium, inducing angiogenesis in rat uterine injury, and improving pregnancy outcomes. In addition, the remarkable observation is that transplantation of ovCYR61 En-PSCs increased the number of embryos implanted at injured sites in rat.

\section{Additional files}

Additional file 1: Figure S1. En-PSCs with different CYR61 expression levels. A CYR61 was detected by Western Blot in transfected En-PSCs. B CCK-8 assay was used to detect the proliferation of transfected En-PSCs. C Wound-healing assay was used to detect the migration effect of EnPSCs supernatant on ESCs. Scale bar, $500 \mu \mathrm{m}$. D The percentage of cell migration was detected in wound-healing experiments after $24 \mathrm{~h}$. E CCK8 assay was used to detect the proliferation of En-PSCs supernatant on the ESCs. Bars represent the means \pm S.E.M. of three independent experiments performed in triplicate. Data were presented as mean + SEM. ${ }^{*} P<0.05$, ${ }^{* *} P<0.01$, ${ }^{* *} P<0.001$, and ${ }^{* * *} P<0.0001$. (TIF $8624 \mathrm{~kb}$ )

Additional file 2: Figure S2. Morphology of uterine injury following different treatments. Gross view of uterine injures at days 30 and 90 posttransplantation in sham group, collagen/PBS group, the collagen/En-PSCs group, the collagen/si-CYR61 En-PSCs group and the collagen/ov-CYR61 En-PSCs group. (TIF $5149 \mathrm{~kb}$ )

Additional file 3: Table S3. Secreted protein in En-PSCs supernatant. (DOCX $52 \mathrm{~kb}$ )

\section{Abbreviations}

Ang1: Angiopoietin-1; ATRA: All-trans-retinoic acid; bFGF: Fibroblast growth factor-basic; BSA: Bovine serum albumin; CCN1: CCN family member 1; CTGF: Connective tissue growth factor; CYR61: Cysteine-rich angiogenic inducer 61; DAPI: 4',6-Diamidino-2-phenylindole; ECM: Extracellular matrix; eMSC: Endometrial MSC; En-PSCs: Endometrial perivascular cells;

ECM: Extracellular matrix; ESCs: Endometrial stromal cells; FBS: Fetal bovine serum; FITC: Fluorescein isothiocyanate; HUVECs: Human umbilical vein endothelial cells; NF-M: Neurofilament medium poclypeptide; NSE: Neuronspecific enolase; PBS: Phosphate-buffered saline; PE: Phycoerythrin;

SD: Sprague-Dawley; SEM: Standard error of the mean; MSCs: Mesenchymal stem cells; VEGF: Vascular endothelial growth factor; VEGFR2: Vascular endothelial growth factor receptor 2; vWF: von Willebrand factor; a-SMA: asmooth muscle actin

\section{Acknowledgements}

The authors would like to thank Yanjun Yang and Lu Xu for the help in the experimental methods and Dr. Rui Huang for the figures' preparations.

\section{Funding}

This work is supported through Lijun Ding by grants from National Key Research and Development Program of China (2018YFC1004700), Nature Science Foundation of China $(81871128,81571391,81401166)$ and Nanjing Medical Science Development Project (ZKX16042, JQX2014004). Prof. Haixiang 
Sun is supported by a grant from Jiangsu Province Social Development Project (BE2018602). Prof. Yali Hu is supported by the grants from National Key Research and Development Program of China (2018YFC1004404) and Jiangsu Province Social Development Project (BE2016612). Prof. Guijun Yan is supported by a grant from National Key Research and Development Program of China (2018YFC1004401). This work is supported by the Fund for Shanxi "1331 Project" Key Subjects Construction (XK201708) and the Fund for Shanxi Key Subjects Construction.

\section{Availability of data and materials}

The datasets generated during and/or analyzed during the current study are available from the corresponding author on reasonable request.

\section{Authors' contributions}

$H S$, LD, and HL conceived the study, designed the experiments, and revised the manuscript. LD and ZL designed the experiments, revised the manuscript, and contributed to the En-PSCs isolation, culture, and identification. ZL participated in the establishment of the tube formation assays, transwell migration assays, the rat model, transplantation of collagen/En-PSCs, histological analysis, and the fertility test and drafted the manuscript. $Z \mathrm{~L}$, $G Y, Q D, F Y$, and $X S$ participated in the establishment of the rat model and transplantation of collagen/En-PSCs. ZL, XL, YL, YD, HZ, XZ, YH, BP, and LD performed the statistical analysis of all the experimental data. All authors read and approved the final manuscript.

\section{Ethics approval and consent to participate}

Human endometrial tissues were obtained from consenting donors with approval from the Ethics Review Board of the Drum Tower Hospital Affiliated to Nanjing University.The animal experiments were conducted according to the guidelines of the Experimental Animals Management Committee (Jiangsu Province, China) and were approved by the Ethics Review Board for Animal Studies of the Drum Tower Hospital Affiliated to Nanjing University Medical School.

\section{Consent for publication}

Not applicable.

\section{Competing interests}

The authors declare that they have no competing interests.

\section{Publisher's Note}

Springer Nature remains neutral with regard to jurisdictional claims in published maps and institutional affiliations.

\section{Author details}

'Department of Histology and Embryology of Shanxi Medical University, Taiyuan 030001, China. ${ }^{2}$ Center for Reproductive Medicine, Department of Obstetrics and Gynecology, the Affiliated Drum Tower Hospital of Nanjing University Medical School, Nanjing 210008, China. ${ }^{3}$ Department of Medical Imaging, Jinling Hospital, Nanjing University Medical School, Nanjing 210002, China. ${ }^{4}$ Center for Experimental Animal, the Affiliated Drum Tower Hospital of Nanjing University Medical School, Nanjing 210008, China. ${ }^{5}$ Department of Obstetrics and Gynecology, the Affiliated Drum Tower Hospital of Nanjing University Medical School, Nanjing 210008, China. ${ }^{6}$ Department of Experimental Medicine, the Affiliated Drum Tower Hospital of Nanjing University Medical School, Nanjing 210008, China. ${ }^{7}$ UKMRC Center for Regenerative Medicine and Center for Cardiovascular Science, University of Edinburgh, Edinburgh, Scotland, UK. ${ }^{8}$ Clinical Center for Stem Cell Research, the Affiliated Drum Tower Hospital of Nanjing University Medical School, Nanjing 210008, China. ${ }^{9}$ Key Laboratory of Pharmaceutical Biotechnology, Nanjing University, Nanjing, China.

\section{Received: 5 February 2019 Revised: 25 April 2019} Accepted: 21 May 2019 Published online: 18 June 2019

\section{References}

1. March CM. Asherman's syndrome. Semin Reprod Med. 2011;29(2):83-94.

2. Naji O, Wynants L, Smith A, Abdallah Y, Saso S, Stalder C, et al. Does the presence of a caesarean section scar affect implantation site and early pregnancy outcome in women attending an early pregnancy assessment unit? Hum Reprod. 2013;28(6):1489-96.
3. Hanstede MM, van der Meij E, Goedemans L, Emanuel MH. Results of centralized Asherman surgery, 2003-2013. Fertil Steril. 2015;104(6):1561-8.e1.

4. Salazar CA, Isaacson K, Morris S. A comprehensive review of Asherman's syndrome: causes, symptoms and treatment options. Curr Opin Obstet Gynecol. 2017;29(4):249-56.

5. Chen Y, Chang Y, Yao S. Role of angiogenesis in endometrial repair of patients with severe intrauterine adhesion. Int J Clin Exp Pathol. 2013;6(7): 1343-50.

6. Ding L, Li X, Sun H, Su J, Lin N, Peault B, et al. Transplantation of bone marrow mesenchymal stem cells on collagen scaffolds for the functional regeneration of injured rat uterus. Biomaterials. 2014;35(18):4888-900.

7. McLennan $\mathrm{CE}$, Rydell $\mathrm{AH}$. Extent of endometrial shedding during normal menstruation. Obstet Gynecol. 1965;26(5):605-21.

8. Chan RW, Schwab KE, Gargett CE. Clonogenicity of human endometrial epithelial and stromal cells. Biol Reprod. 2004;70(6):1738-50.

9. Gargett CE. Uterine stem cells: what is the evidence? Hum Reprod Update. 2007;13(1):87-101.

10. Schwab KE, Gargett CE. Co-expression of two perivascular cell markers isolates mesenchymal stem-like cells from human endometrium. Hum Reprod. 2007;22(11):2903-11.

11. Gargett CE, Schwab KE, Deane JA. Endometrial stem/progenitor cells: the first 10 years. Hum Reprod Update. 2016;22(2):137-63.

12. Crisan M, Yap S, Casteilla L, Chen CW, Corselli M, Park TS, et al. A perivascular origin for mesenchymal stem cells in multiple human organs. Cell Stem Cell. 2008;3(3):301-13.

13. Spitzer TL, Rojas A, Zelenko Z, Aghajanova L, Erikson DW, Barragan F, et al. Perivascular human endometrial mesenchymal stem cells express pathways relevant to self-renewal, lineage specification, and functional phenotype. Biol Reprod. 2012;86(2):58.

14. Dalkara T, Gursoy-Ozdemir Y, Yemisci M. Brain microvascular pericytes in health and disease. Acta Neuropathol. 2011;122(1):1-9.

15. Ansell DM, Izeta A. Pericytes in wound healing: friend or foe? Exp Dermatol. 2015;24(11):833-4.

16. Farrington-Rock C, Crofts NJ, Doherty MJ, Ashton BA, Griffin-Jones C, Canfield AE. Chondrogenic and adipogenic potential of microvascular pericytes. Circulation. 2004;110(15):2226-32.

17. Collett GD, Canfield AE. Angiogenesis and pericytes in the initiation of ectopic calcification. Circ Res. 2005:96(9):930-8.

18. Alliot-Licht B, Bluteau G, Magne D, Lopez-Cazaux S, Lieubeau B, Daculsi G, et al. Dexamethasone stimulates differentiation of odontoblast-like cells in human dental pulp cultures. Cell Tissue Res. 2005;321(3):391-400.

19. Chen WC, Baily JE, Corselli M, Diaz ME, Sun B, Xiang G, et al. Human myocardial pericytes: multipotent mesodermal precursors exhibiting cardiac specificity. Stem Cells. 2015;33(2):557-73.

20. Jay P, Berge-Lefranc JL, Marsollier C, Mejean C, Taviaux S, Berta P. The human growth factor-inducible immediate early gene, CYR61, maps to chromosome 1p. Oncogene. 1997;14(14):1753-7.

21. Mo FE, Muntean AG, Chen CC, Stolz DB, Watkins SC, Lau LF. CYR61 (CCN1) is essential for placental development and vascular integrity. Mol Cell Biol. 2002;22(24):8709-20.

22. Jun Jl, Lau LF. The matricellular protein CCN1 induces fibroblast senescence and restricts fibrosis in cutaneous wound healing. Nat Cell Biol. 2010;12(7): 676-85.

23. Brigstock DR. The connective tissue growth factor/cysteine-rich 61/ nephroblastoma overexpressed (CCN) family. Endocr Rev. 1999;20(2): 189-206.

24. Krupska I, Bruford EA, Chaqour B. Eyeing the Cyr61/CTGF/NOV (CCN) group of genes in development and diseases: highlights of their structural likenesses and functional dissimilarities. Hum Genomics. 2015;9:24.

25. Lee S, Elaskandrany M, Lau LF, Lazzaro D, Grant MB, Chaqour B. Interplay between CCN1 and Wnt5a in endothelial cells and pericytes determines the angiogenic outcome in a model of ischemic retinopathy. Sci Rep. 2017;7(1): 1405

26. Li Y, Qi W, Song X, Lv S, Zhang H, Yang Q. Huaier extract suppresses breast cancer via regulating tumor-associated macrophages. Sci Rep. 2016;6:20049.

27. Li X, Sun H, Lin N, Hou X, Wang J, Zhou B, et al. Regeneration of uterine horns in rats by collagen scaffolds loaded with collagen-binding human basic fibroblast growth factor. Biomaterials. 2011:32(32):8172-81.

28. Xu L, Ding L, Wang L, Cao Y, Zhu H, Lu J, et al. Umbilical cord-derived mesenchymal stem cells on scaffolds facilitate collagen degradation via upregulation of MMP-9 in rat uterine scars. Stem Cell Res Ther. 2017;8(1):84. 
29. Dominici M, Le Blanc K, Mueller I, Slaper-Cortenbach I, Marini F, Krause D, et al. Minimal criteria for defining multipotent mesenchymal stromal cells. The International Society for Cellular Therapy position statement. Cytotherapy. 2006:8(4):315-7.

30. Leach JK, Kaigler D, Wang Z, Krebsbach PH, Mooney DJ. Coating of VEGFreleasing scaffolds with bioactive glass for angiogenesis and bone regeneration. Biomaterials. 2006;27(17):3249-55.

31. Konig MA, Canepa DD, Cadosch D, Casanova E, Heinzelmann M, Rittirsch D, et al. Direct transplantation of native pericytes from adipose tissue: a new perspective to stimulate healing in critical size bone defects. Cytotherapy. 2016;18(1):41-52.

32. Schwab KE, Chan RW, Gargett CE. Putative stem cell activity of human endometrial epithelial and stromal cells during the menstrual cycle. Fertil Steril. 2005;84(Suppl 2):1124-30.

33. Meng X, Ichim TE, Zhong J, Rogers A, Yin Z, Jackson J, et al. Endometrial regenerative cells: a novel stem cell population. J Transl Med. 2007;5:57.

34. Murphy MP, Wang H, Patel AN, Kambhampati S, Angle N, Chan K, et al. Allogeneic endometrial regenerative cells: an "Off the shelf solution" for critical limb ischemia? J Transl Med. 2008;6:45.

35. Meirelles Lda S, Fontes AM, Covas DT, Caplan Al. Mechanisms involved in the therapeutic properties of mesenchymal stem cells. Cytokine Growth Factor Rev. 2009:20(5-6):419-27.

36. Hall-Glenn F, De Young RA, Huang BL, van Handel B, Hofmann JJ, Chen TT, et al. CCN2/connective tissue growth factor is essential for pericyte adhesion and endothelial basement membrane formation during angiogenesis. PLoS One. 2012;7(2):e30562.

37. Suri C, Jones PF, Patan S, Bartunkova S, Maisonpierre PC, Davis S, et al. Requisite role of angiopoietin-1, a ligand for the TIE2 receptor, during embryonic angiogenesis. Cell. 1996;87(7):1171-80.

38. Kappou D, Sifakis S, Konstantinidou A, Papantoniou N, Spandidos DA. Role of the angiopoietin/tie system in pregnancy (review). Ex Ther Med. 2015 9(4):1091-6.

39. Mo FE, Lau LF. The matricellular protein CCN1 is essential for cardiac development. Circ Res. 2006;99(9):961-9.

40. Kireeva ML, Lam SC, Lau LF. Adhesion of human umbilical vein endothelia cells to the immediate-early gene product Cyr61 is mediated through integrin alphavbeta3. J Biol Chem. 1998;273(5):3090-6.

41. Blanco R, Gerhardt H. VEGF and Notch in tip and stalk cell selection. Cold Spring Harb Perspect Med. 2013;3(1):a006569.

42. Haque I, Mehta S, Majumder M, Dhar K, De A, McGregor D, et al. Cyr61/ CCN1 signaling is critical for epithelial-mesenchymal transition and stemness and promotes pancreatic carcinogenesis. Mol Cancer. 2011;10:8.

43. Chintala H, Krupska I, Yan L, Lau L, Grant M, Chaqour B. The matricellular protein $\mathrm{CCN} 1$ controls retinal angiogenesis by targeting VEGF, Src homology 2 domain phosphatase-1 and Notch signaling. Development. 2015;142(13):2364-74

44. Choi JS, Kim KH, Lau LF. The matricellular protein CCN1 promotes mucosal healing in murine colitis through IL-6. Mucosal Immunol. 2015;8(6):1285-96.

45. Tabatabaei FS, Ai J. Mesenchymal endometrial stem/stromal cells for hard tissue engineering: a review of in vitro and in vivo evidence. Regen Med. 2017;12(8):983-95

46. Laino G, Graziano A, d'Aquino R, Pirozzi G, Lanza V, Valiante S, et al. An approachable human adult stem cell source for hard-tissue engineering. J Cell Physiol. 2006;206(3):693-701

Ready to submit your research? Choose BMC and benefit from:

- fast, convenient online submission

- thorough peer review by experienced researchers in your field

- rapid publication on acceptance

- support for research data, including large and complex data types

- gold Open Access which fosters wider collaboration and increased citations

- maximum visibility for your research: over $100 \mathrm{M}$ website views per year

At $\mathrm{BMC}$, research is always in progress.

Learn more biomedcentral.com/submissions 